\title{
Failure and Control of PCBN Tools in the Process of Milling Hardened Steel
}

\author{
Guangyue Wang, Xianliang Zhou, Xuefeng $\mathrm{Wu}^{*}$ and Jing Ma \\ Key Laboratory of Advanced Manufacturing and Intelligent Technology, Ministry of Education, Harbin \\ University of Science and Technology, Harbin 150080, China \\ * Correspondence: wuxuefeng@hrbust.edu.cn; Tel.: +86-451-8639-0538
}

Received: 30 June 2019; Accepted: 10 August 2019; Published: 14 August 2019

\begin{abstract}
The polycrystalline cubic boron nitride (PCBN) milling tool can be used in the mold industry to replace cemented carbide tools to improve machining efficiency and quality. It is necessary to study the tool wear and failure mechanism to increase machining efficiency and extend tool life. Cr12MoV is used to analyze the failure form of PCBN tools in the interrupted cutting of hardened steels at low and high speed conditions in milling experiments. Experimental results show that the failure forms of PCBN tools include chipping and flank wear at low speed, and the failure modes at high speed are flank wear, the surface spalling of the rake face, and the fatigue failure on the flank face. The failure mechanism of different failure forms is analyzed by observing the surface morphology of the tool and using the theory of fracture mechanics. The results show that a high cutting speed should be selected to avoid the early damage of low speed and achieve better application of PCBN tools. At high cutting speed, tool failure is mainly caused by mechanical wear, diffusion wear, and oxidation wear. Moreover, a fatigue crack will occur at the cutting edge on the chamfered tool under thermal-mechanical coupling because of the intergranular fracture of the CBN grain and binder. A large area of accumulated fatigue damage may appear due to the influence of alternating mechanical stress and thermal stress. Finally, the control method to avoid tool failure is presented.
\end{abstract}

Keywords: PCBN tool; hardened steel; hard milling cutter; mold machining; tool failure

\section{Introduction}

With the development of automobile technology, the automobile mold is in great demand in automobile production, especially for medium and large-sized covering parts of high-grade cars [1]. The tool steel $\mathrm{Cr} 12 \mathrm{MoV}$ is a commonly used material for the automobile mold of cover parts. It is a high chromium and carbon steel, with the characteristics of high hardness, strength, and wear resistance. It can reach 60 HRC (Hardness Rockwell C) after heat treatment, so high hardness characteristics tools are used to process the workpiece. Complex end-mills, such as ball-end mills [2,3], circle-segment mills [4,5], are often used in mold machining. At present, cemented carbide tools are usually used for most of the molds, and tool failure in the processing is severe because the cutting tool often suffers from the large cutting force, high temperature, and intermittent shock on milling process resulting in rapid tool wear and low production efficiency $[6,7]$.

Many methods are used to improve tool performance. Luo [8] changed the multi-axis milling strategy based on shifting the active cutting edge to average the wear of the cutting edge on the cutter, thus prolonging the tool life. Changing the lubrication method can also increase the tool life. The comprised dry, wet, and minimum quantity lubrication (MQL) method was identified as the best cooling method for minimum tool wear and surface roughness [9]. Moreover, the fluid's content used in MQL has an influence on the chip morphology and tool performance [10]. In addition, changing tool materials is the most important way to improve tool performance. Polycrystalline cubic boron 
nitride (PCBN) cutting tools are the preferred tool material due to excellent mechanical properties of higher hardness strength and wear resistance than other tool materials at high temperature. They are frequently used in the turning of hard and wear-resistant materials, such as hardened steels, superalloy, and even ceramics [11-14]. Numerous studies investigate the machining performance and tool life in PCBN hard turning [15-17]. Progressive flank wear, micro-chipping, and tool breakage easily occur due to critical crater wear [18]. For different cutting tools and workpiece materials, cutting speed is the main factor affecting the tool life, and it usually has a critical value after which the tool life of the cemented carbide tool will be lower than the PCBN cutting tool.

In recent years, scholars have focused on the research of milling using the PCBN cutting tool. The results show that with a smaller cutting force [19], better surface quality [20], and a higher volume of metal removal [21] can be obtained by using PCBN tools compared with carbide-coated tools in processing hardened steel materials.

It is observed that surface roughness ( $\mathrm{Ra})$ is in the range of 0.2 to $0.3 \mu \mathrm{m}$ using a PCBN ball end tool, compared with 0.4 to $0.6 \mu \mathrm{m}$ using the cemented tungsten carbide tool, at the cutting speed of $400 \mathrm{~m} / \mathrm{min}$ in the milling of DIEVAR tool steel [22]. For milling, there is still a speed below which the tool life of cemented carbide is less than the tool life of PCBN. The life of cemented carbide tools can be higher than that of PCBN tools when the cutting speed is less than $400 \mathrm{~m} / \mathrm{min}$ in ball-end milling. When the cutting speed is more than $400 \mathrm{~m} / \mathrm{min}$, the wear of the cemented carbide tool is serious, and the PCBN tool exhibits good cutting performance [23]. Wojciechowskl et al. [24,25] conducted a series of experiments in milling of hardened steel using PCBN tools, their results indicated that tool life of cemented carbide tools can be higher than that obtained using PCBN tools in a specific range of cutting speed. The surface finish and tool life can be improved by optimizing machining parameters. Therefore, PCBN tools also have a certain range of use correlated to cutting speed; the tool life decreases first and then increases when the cutting speed increases, due to adhesion, oxidation, and thermal cracking for high cutting temperatures.

In addition to cutting parameters, other factors can impact tool life. Fatih et al. [26] studied the wear performance of a PCBN tool and TiN coated PCBN in face milling of die steel 90 MnCrV8 (61 HRC). The non-coated PCBN tool had a more stable depth and length tool wear rate than the TiN coated PCBN. The content of CBN will also affect the cutting performance and tool wear. Chou $[27,28]$ studied the cutting force of M50 hardened steel in interrupted cylindrical turning with PCBN tools with different $\mathrm{CBN}$ contents. Low CBN content cutting tools perform better than high CBN content tools in the interrupted cutting of hardened PM M50. A similar conclusion was obtained with the intermittent hard turning of bearing steel [29]; the cutting performance of the tool with a lower content of CBN was better than that of the tool with a high content of PCBN in terms of tool wear and surface integrity.

The wear mechanism of PCBN involved in the machining processing of hard steel is quite complicated. Koshy et al. considered that the chipping, abrasive, and adhesive wear are the primary mechanisms for PCBN tool wear [19]. Boing et al. [30] found that there is a nonlinear relationship between abrasive wear, adhesive wear, diffusion wear, and material hardness using a three-dimensional wear parameter method depending on the mechanical load, thermal load, and chemical load generated in the machining process. The performance of PCBN tools with different cutting tools, cutting parameters, and working materials are limited by crater wear, flank wear, edge cutting, or a combination of these factors [31]. When PCBN tools are applied to mold processing, workers are concerned about when it will fail and how to avoid unnecessary failure.

However, there are few studies on the failure and failure control of hardened steel tools in PCBN tool milling, which restricts the application of PCBN tools in the precision machining of automobile covers. To investigate the rule of the tool wear and control tool damage, milling experiments of Cr12MoV using PCBN a ball-end milling cutter was conducted first, to analyze the failure mode and failure mechanism of a PCBN tool in the milling process of hardened steel. After obtaining the influence of CBN content and blade size on tool wear, the appropriate insert was used to analyze the influence of cutting speed on tool damage. The tool wear and failure conditions at low-speed 
and high-speed were analyzed separately. Finally, an attempt was made to investigate the method of avoiding unreasonable failures at low and high cutting speed to provide the theoretical basis for the application of the PCBN tool in the machining of automobile covering parts.

\section{Experimental Set-Up}

The tool used in the test was a machine-clamped ball-end milling cutter with a diameter of $20 \mathrm{~mm}$. The workpiece material was die steel $\mathrm{Cr} 12 \mathrm{MoV}$ with the hardness of $60 \mathrm{HRC}$ after heat treatment. The milling cutters were BNMM-200S-S25C (DIJET Inc., Osaka, Japan). The tool overhang was 100vmm. The PCBN milling inserts were tipped inserts created by welding the PCBN onto the cemented carbide tool. The PCBN materials were BN100 (80\% CBN, Sumitomo Inc. Itami, Hyogo, Japan).with a rake angle of $0^{\circ}$, clearance angle of $13^{\circ}$, chamfering width of $0.2 \mathrm{~mm}$ and chamfer Angle of $15^{\circ}$ without coating. The blunt radius of the cutting edge was $0.060 \mathrm{~mm}$. The cemented carbide insert was BNM-200 GRADE JC5015 (DIJET Inc., Osaka, Japan) with a diameter of $20 \mathrm{~mm}$, and the coating was TiAlN. The blunt radius of the cutting edge was $0.054 \mathrm{~mm}$. The experiments were carried out on a four-axis machining center VDL-1000E (Dalian Machine Tool Corporation, Dalian, China). The milling cutter was placed vertically, and the workpiece was placed at an angle of $30^{\circ}$ inclination. The milling method was up milling. Cutting speed had an important influence on the tool wear form and failure process for different material tools. This paper mainly analyzes the influence of cutting speed on the milling of hardened steel tools by PCBN tools. In addition to the cutting speed, the cutting parameters were set to a fixed value. The cutting depth $\left(a_{p}=0.3 \mathrm{~mm}\right)$ and the feed per tooth $\left(f_{z}=0.15 \mathrm{~mm} / \mathrm{z}\right)$ was set to a fixed value, and the cutting speed was based on the cutting speed of the maximum point of the cutting edge involved in cutting.

Although PCBN tools are generally recommended for use in the case of high machining speed, in the actual machining of the mold, the cutting speed cannot be kept at a high speed all the time since the cutting edge of the ball-end mill, and the workpiece is not in a fixed position. Thus, the cutting speed was set from $50 \mathrm{~m} / \mathrm{min}$ to $350 \mathrm{~m} / \mathrm{min}$ to study the effect of cutting speed on tool wear and failure. During the cutting test, the insert was removed every 2 min of cutting, and the rake face, the flank face, and the tip of the tool was observed using a digital microscope of VHX-1000 (KEYENCE Inc., Osaka, Japan). The SEM of SUPRA55 was used to observe the morphology of the failed tool, focusing on whether cracks were generated. The experimental setup for milling test is shown in Figure 1.

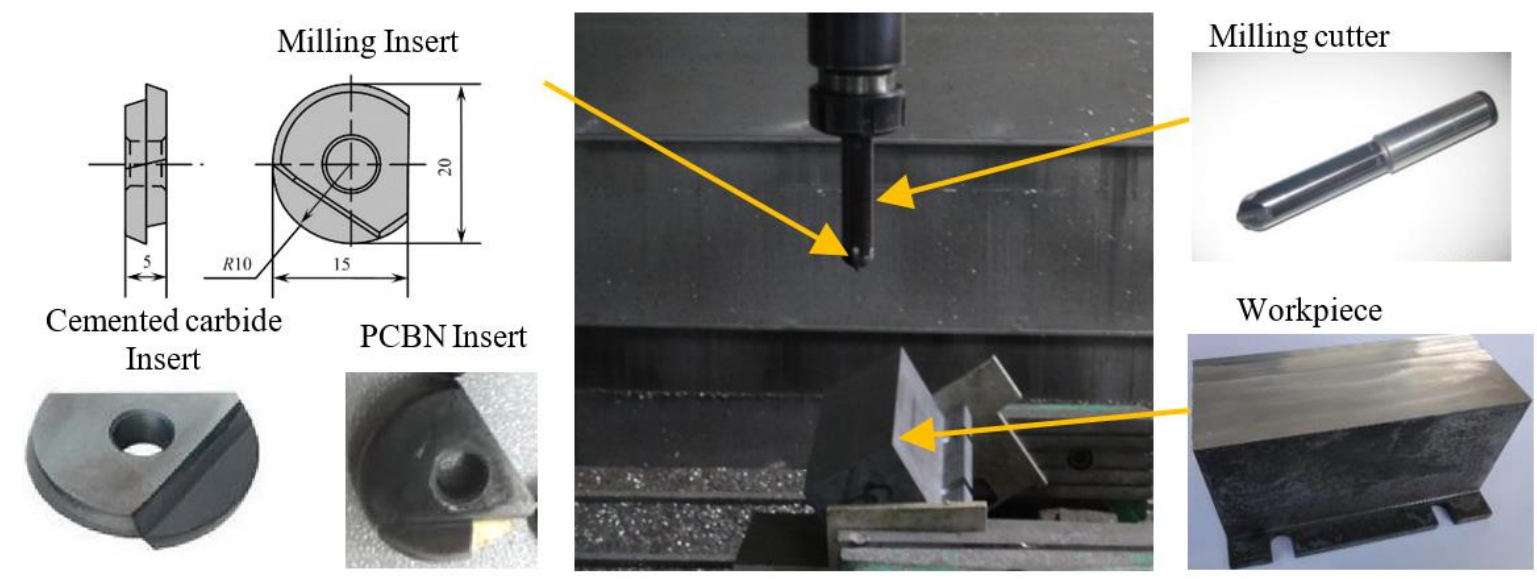

Figure 1. The experimental setup for milling test.

\section{Results and Discussion}

\subsection{Influence of Machining Parameters on Cutting Force}

Cutting forces in milling experiments at various cutting speed for different tool materials are shown in Figure 2. $F_{x}$ is the radial force, $F_{y}$ is the feed force, and $F_{z}$ is the axial force. The cutting 
force of the carbide tool increased rapidly when the cutting speed reached $250 \mathrm{~m} / \mathrm{min}$ because a carbide tool cannot withstand high temperatures at high cutting speeds, leading to significant wear and even chipping. When the cutting speed was $350 \mathrm{~m} / \mathrm{min}$, the cutting force in the machining using cemented carbide tools was much larger than using PCBN tools. The cutting performance of the PCBN tools is better reflected with increasing cutting speed due to the softening effect of the workpiece at high temperature. The impact and resistance to the tool are reduced, and the cutting force shows a decreasing trend. Therefore, cemented carbide is not suitable for high-speed cutting, as mentioned in the references. A mixed machining strategy can be used to select different tool materials in machining the mold.

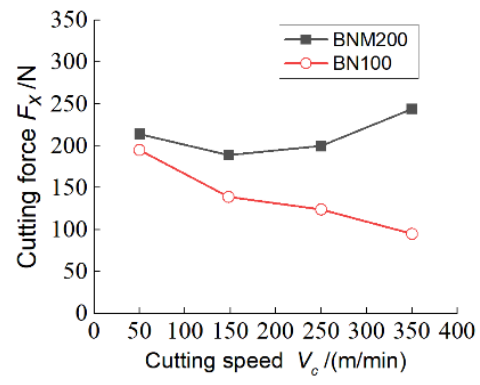

(a)

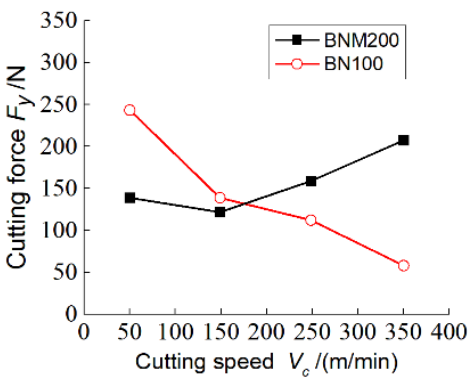

(b)

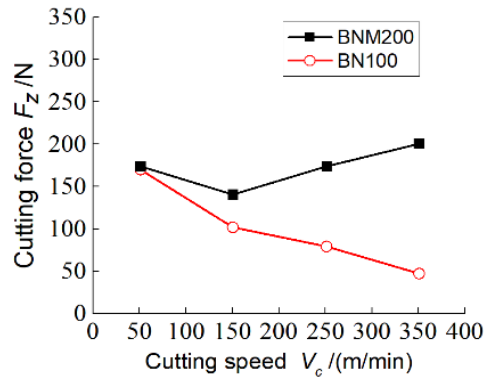

(c)

Figure 2. Effect of cutting speed on cutting force: (a) Radial force; (b) Force in feed direction; (c) Axial force.

Experiments with a different cutting edge of PCBN tools (BN100) were conducted; the cutting speed was $150 \mathrm{~m} / \mathrm{min}$, and the chamfering width was $0.10 \mathrm{~mm}, 0.15 \mathrm{~mm}, 0.20 \mathrm{~mm}, 0.25 \mathrm{~mm}$, and $0.30 \mathrm{~mm}$, respectively. With the increase of chamfering width, the strength of the cutting-edge increased, and the damage resistance of the rake face and the flank face increases. The insert was damaged with the chamfer width of $0.10 \mathrm{~mm}$ after $13 \mathrm{~min}$, compared with the progressive wear of the tool with the chamfer width of $0.25 \mathrm{~mm}$, as shown in Figure 3. The high-brittle PCBN has poor toughness, and the milling tool needs to be chamfered, which reduces the impact of the intermittent cutting and the probability of impact damage.

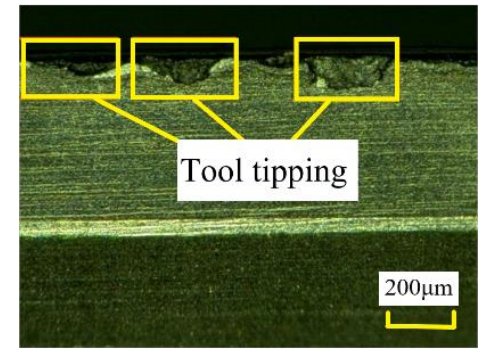

(a)

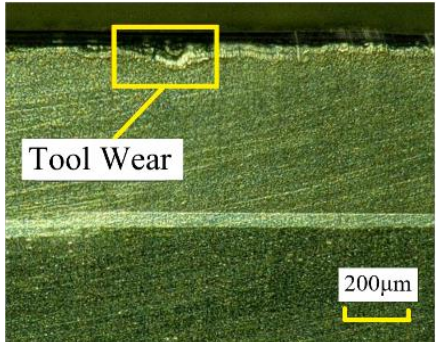

(b)

Figure 3. Effect of chamfer width on resistant breakage ability of flank: (a) Chamfer width of $0.10 \mathrm{~mm}$; (b) Chamfer width of $0.25 \mathrm{~mm}$.

The rake face and the flank face of the cutting tool were observed for a period, and the milling forces were measured when the flank wear was $0.05 \mathrm{~mm}, 0.10 \mathrm{~mm}, 0.15 \mathrm{~mm}, 0.20 \mathrm{~mm}$, and $0.25 \mathrm{~mm}$, respectively. The effects of chamfer width and wear on the feed cutting force are shown in Figure 4. The feed cutting force increased with increasing width of the chamfer. Although the chamfering edge enhances the ability of the tool to resist the intermittent impact and reduces the damage probability of the tool, the cutting force tends to increase as the tool wear increases. It will increase the possibility of causing damage to the next insert. Therefore, for the intermittent milling of hardening steel with 
PCBN tools, the chamfer width of the tool should be selected within a range of more than $0.10 \mathrm{~mm}$ to less than $0.25 \mathrm{~mm}$ to prevent unnecessary failure.

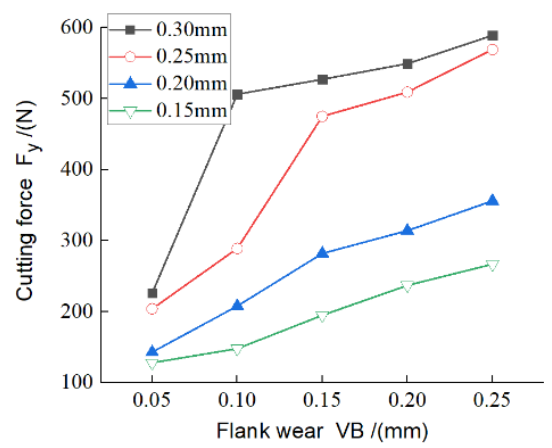

Figure 4. Effect of chamfer width on cutting force under different tool wear.

\subsection{Influence of Machining Parameters on Tool Life}

The tool life of cemented carbide tools and PCBN tools at different cutting speeds are shown in Figure 5. For cemented carbide tools, when the cutting speed was $350 \mathrm{~m} / \mathrm{min}$, the tool was obviously damaged after machining for $60 \mathrm{~min}$. The Co bond cannot withstand higher temperatures and breakage occurs on the rake face because of the characteristics of the cemented carbide itself. When the cutting speed was $150 \mathrm{~m} / \mathrm{min}$ and $250 \mathrm{~m} / \mathrm{min}$, the cutting time before the tool reached the wear standard was significantly shorter than that of the PCBN tool. When the cutting speed was $50 \mathrm{~m} / \mathrm{min}$, the damage occurred after $5 \mathrm{~min}$ of machining using the PCBN tool. However, the cemented carbide tool showed good cutting performance.

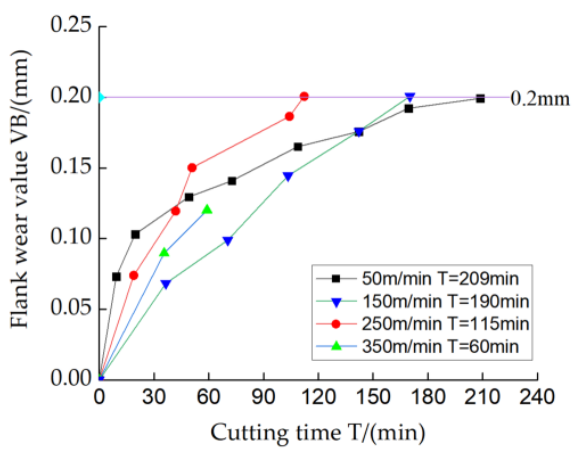

(a)

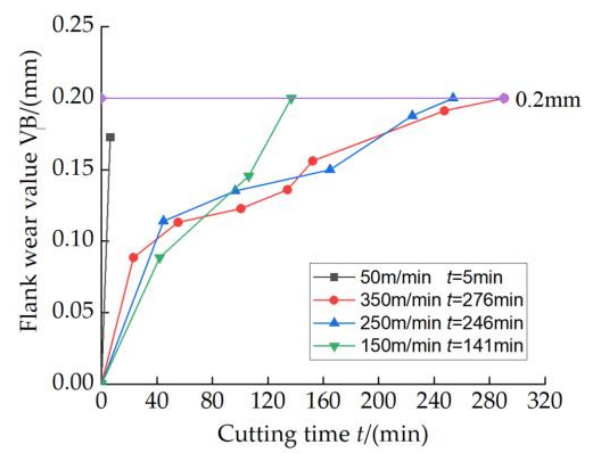

(b)

Figure 5. Influence of cutting speed on tool wear: (a) Tool wear of cemented carbide tools (BNM 200);

(b) Tool wear of polycrystalline cubic boron nitride (PCBN) cutting tools (BN 100).

The CBN tool material consists of CBN grains and binders. The temperature and impact of the machining affect the strength and hardness of the tool during machining and then affects the tool life. The CBN inserts with different CBN content were used in the experiments (HTM2100, 50\% CBN content and BZN9100, 90\% CBN content). The selected cutting speed avoided the speed that was likely to cause low-speed breakage, and the form of wear was mainly in the form of face wear. The tool wear for different CBN content at various cutting speeds is shown in Figure 6. 


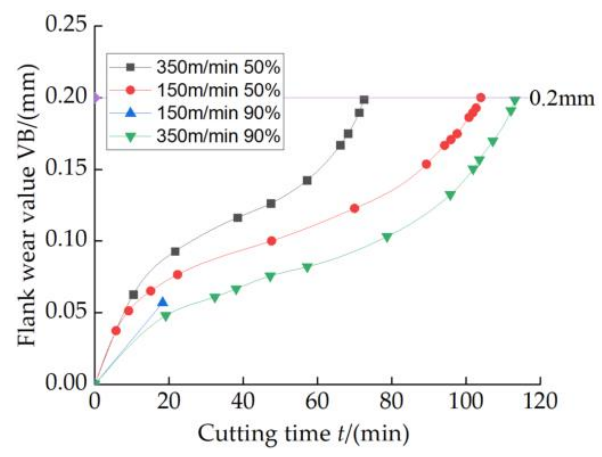

Figure 6. Influence of CBN content on tool wear.

When the cutting speed was $150 \mathrm{~m} / \mathrm{min}$, the CBN tool with a high content will break the larger area of the rake face after $18 \mathrm{~min}$ of cutting. It can be seen that it is not suitable for high content CBN tools at low cutting speed. When the cutting speed was $350 \mathrm{~m} / \mathrm{min}$, the tool can enter the normal wear phase and have a long service life. The cutting performance of the low-content CBN tool was just the opposite. Since the wear resistance and breakage resistance of the tool results from the interaction of force and heat, when the cutting speed was $350 \mathrm{~m} / \mathrm{min}$, the influence of the cutting temperature on the cutting performance of the tool played a leading role. When the cutting temperature was high, the material was softened, and the PCBN tool with high CBN content showed better cutting performance. When the cutting speed was low (less than $350 \mathrm{~m} / \mathrm{min}$ ), the influence of mechanical impact on the tool performance during machining played a leading role. At this time, the cutting force is large, and the PCBN tool with low CBN content shows better impact resistance. Although neither of the two cutting speeds showed breakage, it can be clearly seen that the cutting performance of the tool with lower CBN content at lower cutting speed is more robust.

\subsection{Tool Failure at Low-Speed Cutting}

This type of damage is caused by the chipping from the edge of the tool to the flank of the tool. Generally, the chipping portion is thin on the rake face of the tool, and a large damaged surface is left on the flank face. When machining hardened steel materials with PCBN tools, this low-speed chipping often occurs during processing due to the high strength and hardness of the workpiece and the brittleness of the tool material of the PCBN tool itself. Figure 7 shows the failure mode of the five inserts in the tests at the cutting speed of $150 \mathrm{~m} / \mathrm{min}$. The 1\#, 2\#, and 3\# inserts showed a phenomenon of edge chipping after short cutting times, as shown in Figure 7a-c. When the 4\# insert cut for $26 \mathrm{~min}$, no visible chipping phenomenon was found. However, a large area on the flank face was found to be damaged after $2 \mathrm{~min}$, as shown in Figure 7d. For the 5\# insert, no obvious tool breakage or chipping was observed after cutting $22 \mathrm{~min}$. However, after $2 \mathrm{~min}$, the same phenomenon appeared as with the $4 \#$ insert; that is, the flank face showed considerable damage. 


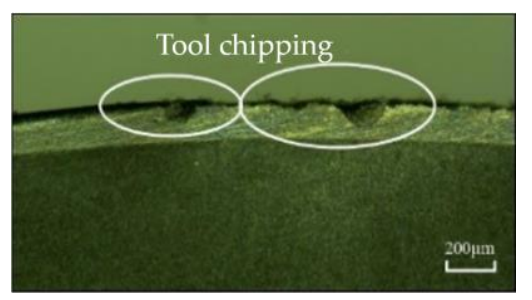

(a)

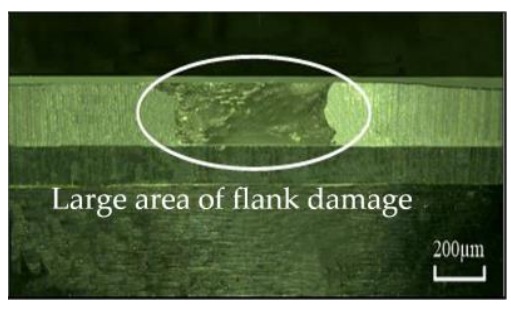

(d)

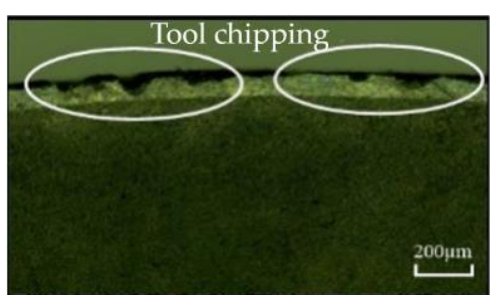

(b)

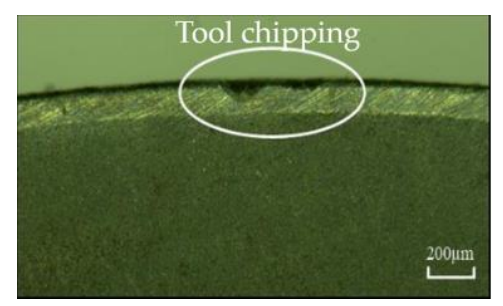

(c)

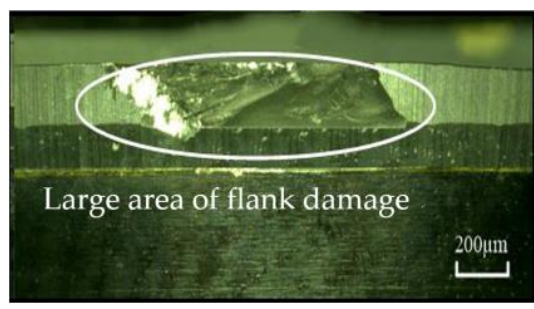

(e)

Figure 7. Tool failure form at cutting speed $150 \mathrm{~m} / \mathrm{min}$ : (a) $t=4 \mathrm{~min}$ (insert 1\#); (b) $t=6$ min (insert 2\#); (c) $t=14 \mathrm{~min}$ (insert 3\#); (d) $t=28 \mathrm{~min}$ (insert 4\#); (e) $t=24 \mathrm{~min}$ (insert 5\#).

The results showed that the failure modes of the hardened steel tool for PCBN tool milling at low-speed conditions were edge chipping and the massive area damage on the flank face. The wear morphology of the insert tip was observed using SEM, as shown in Figure 8. It can be found that cracks appear parallel to the cutting edge on the chipping edge due to the oxide skin or the hard spot on the surface. Therefore, the tool was subjected to a significant impact force after it contacted the hard spot at lower cutting speed, causing a mechanical crack parallel to the cutting edge in the tip portion. The crack propagated until the edge of the insert collapsed. After the surface was removed from the workpiece, the quenching inside the workpiece was uniform. In this case, the edge of the tooltip will be reduced. The experimental results show that the tool has a large area of flank damage after a short machining time if the cutting-edge chipping does not appear. Such damage is mainly caused by the large cutting force; the bending stress of the tool is greater than the bending strength of the tool material itself [28]. So, there will be a limit milling speed when the PCBN tool is used to mill hardened steel. Below this limit milling speed, the tool will withstand the stress more significantly than the material's own bending strength, resulting in damage to the flank of the tool.

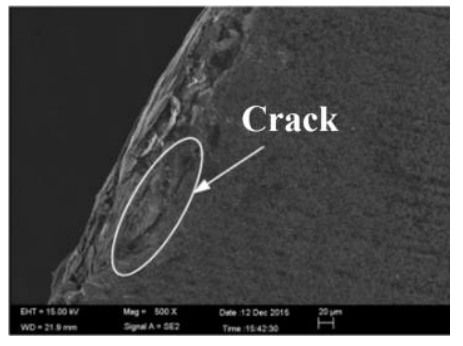

(a)

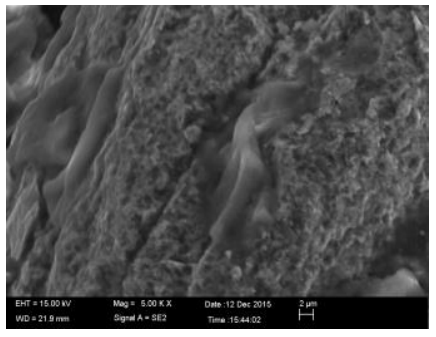

(b)

Figure 8. The microscopic morphology of chipping: (a) The crack area; (b) The magnification of the crack.

\subsection{Tool Failure at High-Speed Damage}

The first type of damage was characterized by an initial period of tool durability or an irregular period that is entirely unpredictable. Correspondingly, this type of damage is caused by the fatigue of the cutter, which has fatigue durability determined by the tool state and working conditions using 
PCBN cutting tool in milling of hardened steel. When the tool cut for a long time, it was subjected to alternating mechanical shock and thermal shock. The micro-cracks may appear due to the brittleness characteristic of the PCBN tool. The tool is damaged in the weakest place while cutting. According to the position of the crack that occurs, the high-speed damage can be specifically classified into damage caused by the rake face crack, the flank crack, and the corporate crack of the front and back flank.

The cutting speed was selected as $350 \mathrm{~m} / \mathrm{min}$ to test the cutting tools, and the other conditions were unchanged. The inserts were observed after every $2 \mathrm{~min}$, as shown in Figures 9-11. The surface of the rake face peels off after 58 min machining in 6\# insert, as shown in Figure 9. At this time, the 6\# insert was not able to continue to use. The results show that flank face wear is the main form of wear. When the cutting test was carried out on 7\# insert after $68 \mathrm{~min}$, the tool flank wear amount reached to $0.2 \mathrm{~mm}$, and the tool failure form was dominated by the flank wear. Experiments were continued to carry out with the insert to study their wear characteristics. After 84 min of machining, the flank of the tool was fatigue-damaged, as shown in Figure 10. The phenomenon was the same while machining 8\#, as shown in Figure 11. There was slight chipping at about $66 \mathrm{~min}$ after the initial flank wear, and the insert began to break after 70 min of cutting. Although the wear of each tool was not the same as the time of wear, the pattern of wear was exactly the same.

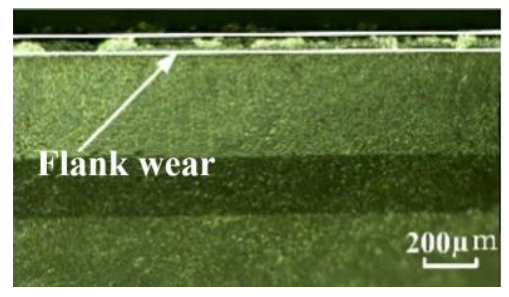

(a)

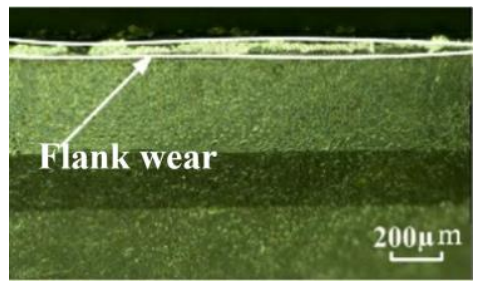

(b)

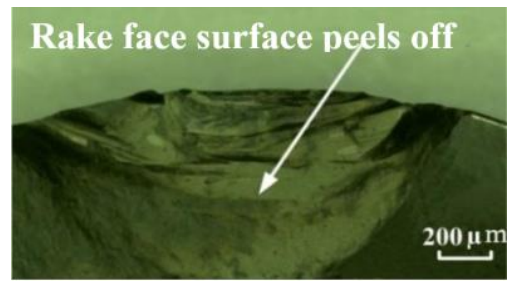

(c)

Figure 9. Tool failure morphology of $6 \#$ cutter insert at different cutting times: (a) $t=32 \mathrm{~min}$; (b) $t=56 \mathrm{~min}$; (c) $t=58 \mathrm{~min}$.

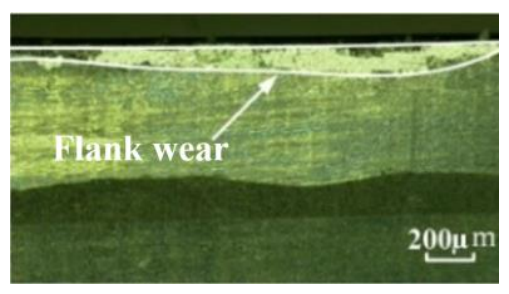

(a)

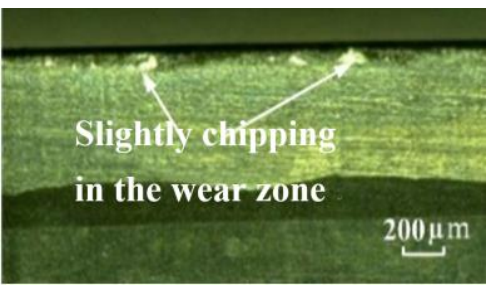

(b)

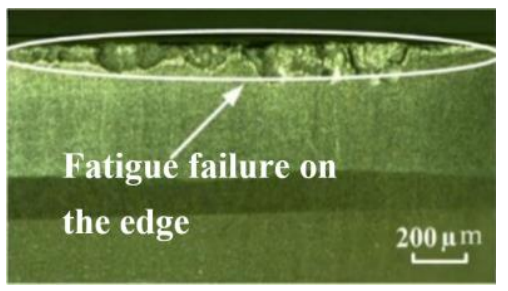

(c)

Figure 10. Tool failure morphology of $7 \#$ cutter insert at different cutting times fatigue failure: (a) $t=18 \mathrm{~min}$; (b) $t=68 \mathrm{~min}$; (c) $t=84 \mathrm{~min}$.

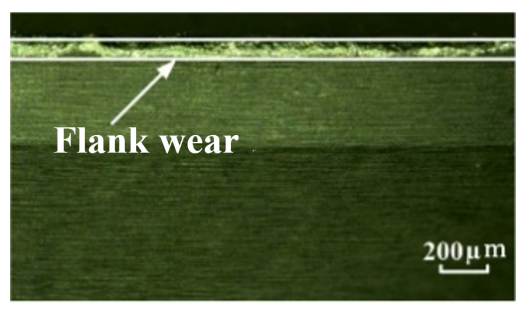

(a)

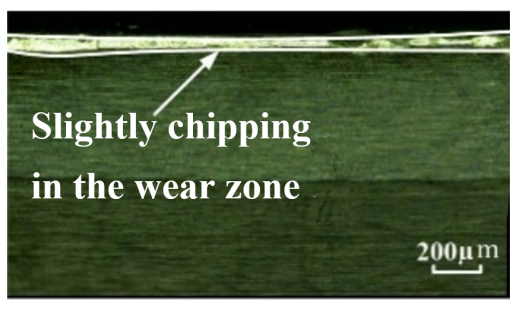

(b)

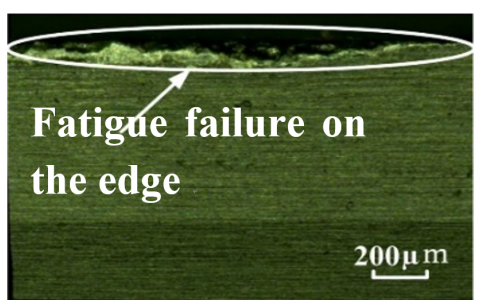

(c)

Figure 11. Tool failure morphology of $8 \#$ cutter insert at different cutting times: (a) $t=18 \mathrm{~min}$; (b) $t=66 \mathrm{~min}$; (c) $t=70 \mathrm{~min}$. 
Under high-speed conditions, the failure modes are (1) flank wear; (2) material peeling on the flank surface; (3) high-speed fatigue damage on the flank surface. The element composition of the flank wear area was detected by EDX to analyze the wear mechanism. It was found that the presence of $\mathrm{Fe}$, $\mathrm{Mn}, \mathrm{Al}$, and $\mathrm{Cr}$ elements were detected in the flank wear region of the tool, and a large number of $\mathrm{O}$ elements were detected as shown in Figure 12b,c. It is indicated that in the hardened steel for milling, in addition to mechanical wear, the flank was accompanied by diffusion wear and oxidative wear.

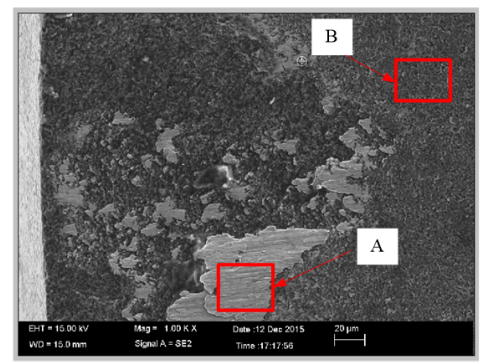

(a)

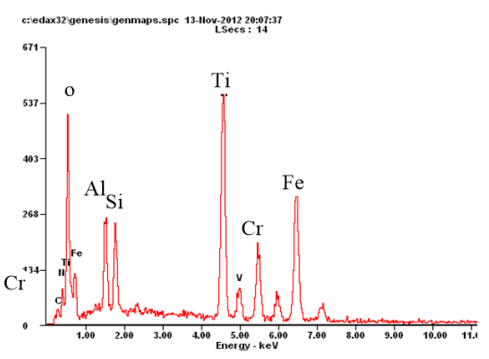

(b)

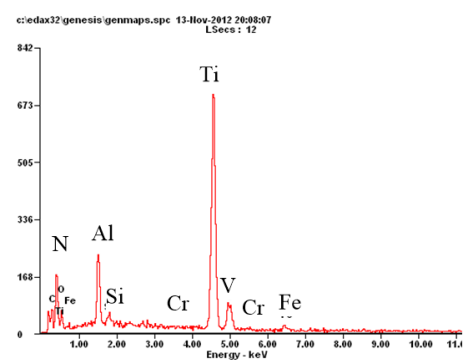

(c)

Figure 12. PCBN cutting tool flank wear morphology: (a) The microstructure of the flank wear; (b) Analysis of element content at A; (c) Analysis of element content at B.

The rake surface of the PCBN tool peeled off, as shown in Figure 13, and the occurrence of fatigue cracks was clearly found in the peel-off area. The fractured form of PCBN tool was mainly along the crystal fracture, accompanied by a small amount of trans-granular fracturing. CBN grains were distributed on both sides of the crack, which was the initial crack form of crack formation. Under the action of alternating load and alternating heat, the crack expanded along the grain boundary and the binder phase. The tool was subjected to alternant load while milling, and under the action of alternating thermal load, the thermal expansion coefficients of CBN grains and binder in the tool material were different, resulting in different deformation rates and different deformation amounts. This caused that the cracks to first appear in the weaker areas (along the crystal crack), and the effect of the alternating force load further accelerated the crack propagation, resulting in fatigue damage on the rake face in the form of peeling of the surface material of the previous flank. Milling of PCBN tools under high-speed conditions, in addition to the occurrence of flank wear after the appearance of the flank, peeling on the rake face and massive area damage on the flank face may happen due to the combination of mechanical stress and thermal stress.

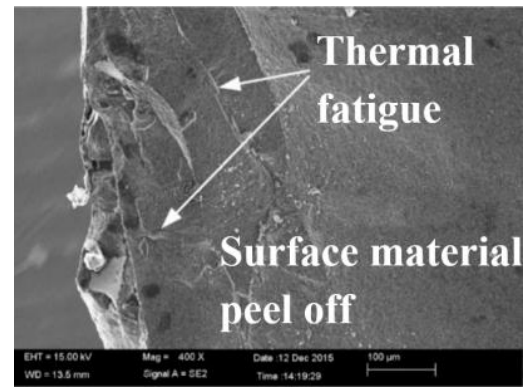

(a)

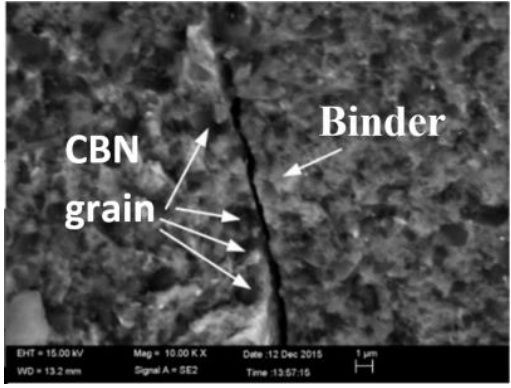

(b)

Figure 13. The microscopic morphology of the PCBN tool rake face after the peeling of the surface material: (a) Microscopic morphology; (b) Tool rake face fatigue crack morphology.

\section{Critical Conditions to Avoid Low-Speed Breakage}

A critical milling speed model needs to be established to avoid the low-speed damage of hardened steel in the intermittent processing of PCBN tools. The milling speed should be higher than the 
theoretical limit milling speed to ensure that the PCBN tool can avoid low-speed damage. The moment of the contact between the tool and the workpiece is shown in Figure 14. The workpiece was placed at an angle to the cutting tool, and the milling method was up milling. The tool and the workpiece had multiple contacts per revolution due to the multiple cutting edges of the tool. The thickness of the cutting layer varied during the cut-in to the cut-out process for each cutting edge rotates at a certain angle, which led to the cyclic bending stress to the insert.

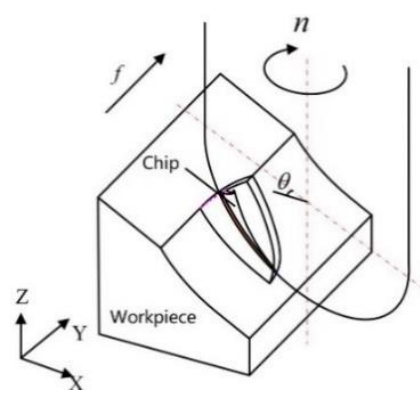

(a)

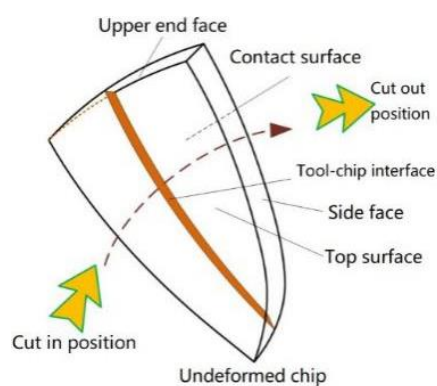

(b)

Figure 14. Schematic diagram of the milling process: (a) Milling of Inclined Plane; (b) Schematic of chip shape.

The parameters were set as the spindle speed of $7000 \mathrm{r} / \mathrm{min}$, cutting depth of $0.3 \mathrm{~mm}$, cutting width of $0.3 \mathrm{~mm}$, feed per tooth of $0.1 \mathrm{~mm} / \mathrm{z}$, and inclination of the workpiece was $10^{\circ}$. Schematic diagram of the change of the insert-to-chip contact area at different corners of the tool is shown in Figure 15. As the tool rotated, the contact area between the tool and the chip changed continuously. The length of the cutting edge, set as L, that participated in the cutting in different tool angles under this parameter is shown in Figure 16.

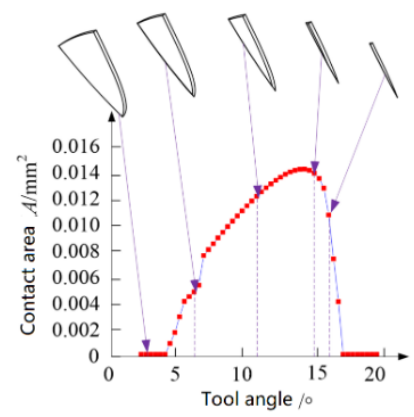

Figure 15. Cutting edge contact area in different tools angles.

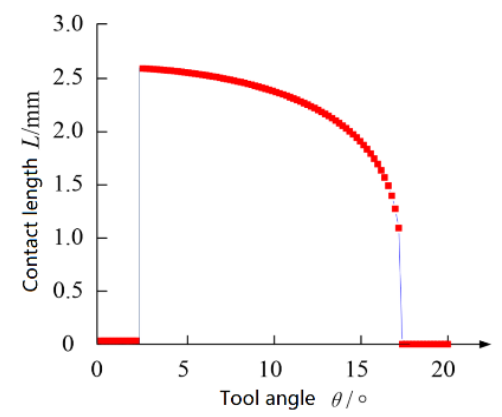

Figure 16. Cutting edge contact length in different tools angles.

The model for the contact area of the chip at any time can be simplified, as shown in Figure 17. 


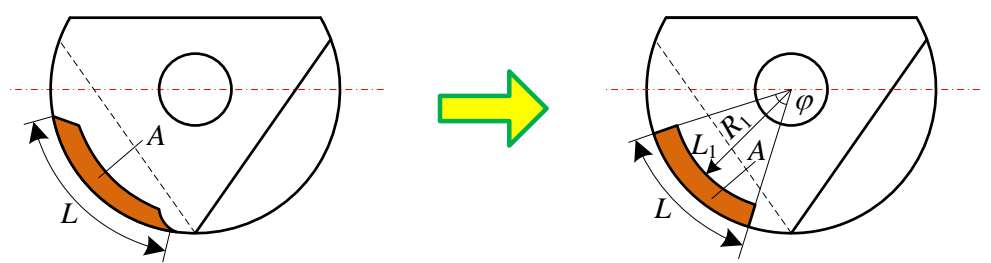

Figure 17. A simplified model of the tool-chip contact area.

The following formula can be obtained from Figure 18:

$$
\begin{gathered}
\varphi=\frac{L}{R}, \\
A=\frac{\varphi}{2}\left(R^{2}-R_{1}^{2}\right), \\
R_{1}=\sqrt{R^{2}-\frac{2 A}{\varphi},} \\
L_{1}=\varphi R_{1},
\end{gathered}
$$

where $A$ represents the contact area of the tool and workpiece, $R_{1}$ represents the inner radius of the chip, $\varphi$ is the angle of the cutting-edge contact position. $L_{1}$ represents the inner length of the chip after simplification. Figure 18 shows the damage of the tooltip during machining. $F$ is the radial force received by the tooltip.

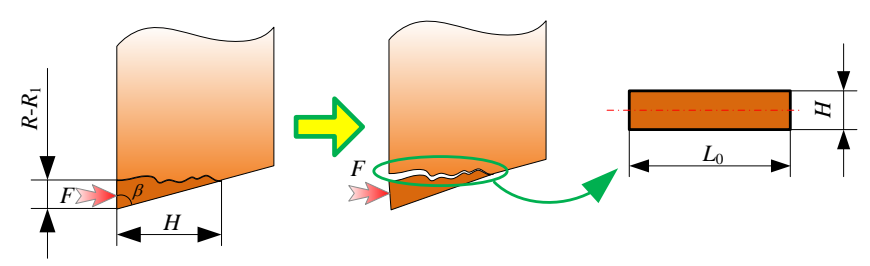

Figure 18. Schematic diagram of stress damage of cutting tool.

The bending stress of the tool can be expressed by the following formula (5):

$$
\sigma_{f}=\frac{M}{Z}
$$

where $M$ is the bending moment, and $\mathrm{Z}$ is the moment of inertia.

$$
\begin{gathered}
M=\frac{1}{2} F\left(R-R_{1}\right), \\
Z=\frac{1}{6}\left(L_{0} H^{2}\right), \\
H=\tan \beta\left(R-R_{1}\right), \\
L_{0}=\left(L+L_{1}\right) / 2 .
\end{gathered}
$$

Therefore, to avoid low-speed impact damage in the PCBN tool interrupted cutting process, the critical conditions are

$$
\sigma_{f}<\sigma_{f \max }
$$

where $\sigma_{f \max }$ is the limit of bending strength. 
By substituting Equations (6)-(9) into Equation (5), the bending stress of the tool is

$$
\sigma_{f}=\frac{6 F_{i}(\theta)}{L_{i}(\theta)+\frac{L_{i}(\theta)}{R} \sqrt{R^{2}-\frac{2 A_{i}(\theta)}{\left(\frac{L_{i}(\theta)}{R}\right)}}\left(R-\sqrt{\left.R^{2}-\frac{2 A_{i}(\theta)}{\left(\frac{L_{i}(\theta)}{R}\right)}\right) \tan ^{2} \beta}\right.},
$$

where $\theta$ is the angle of the tool turns. When the angle of the tool is $\theta$ at time $i$, the bending stress of the tool is related to milling force, contact length, the contact area of the tool and the chip. And these parameters are related to the angle of the tool, cutting depth, cutting speed, cutting with, feed per tooth, tool parameters, etc., as shown in Equation (12). Where $F_{i}(\theta)$ is the component of milling force perpendicular to the rake face when the angle of the tool is $\theta$. And it can be obtained by the cutting test or finite element simulation method. The length of the contact inserts $\operatorname{Li}(\theta)$, and contact area of tool and chip $A_{i}(\theta)$ can be obtained using 3D modeling software. The relationship between these parameters and the tool angle are shown in Figure 19. Therefore, the values of the three corners are brought into the Equation (11) to obtain the bending stress of the tool under the angle of rotation.

$$
\left\{\begin{array}{l}
F_{i}(\theta)=f_{1}\left(\theta, a_{p}, v, a_{e}, f_{z}\right) \\
L_{i}(\theta)=f_{2}\left(\theta, a_{p}, v, a_{e}, f_{z}\right) \\
A_{i}(\theta)=f_{3}\left(\theta, a_{p}, v, a_{e}, f_{z}\right)
\end{array} .\right.
$$

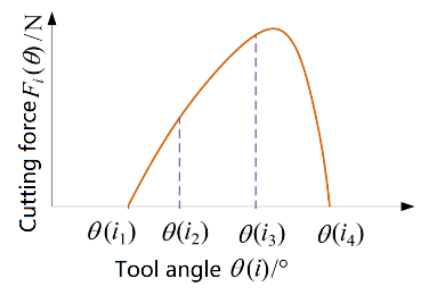

(a)

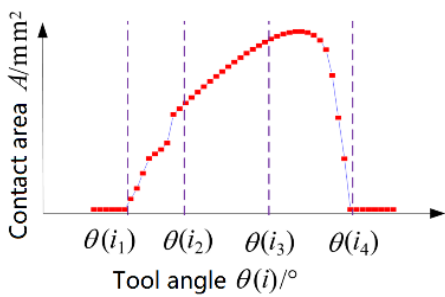

(b)

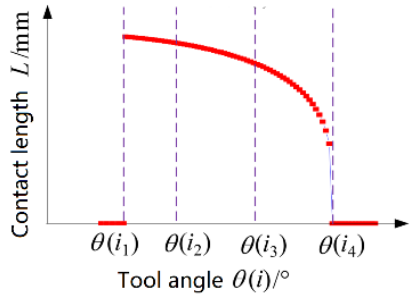

(c)

Figure 19. Correspondence relationship in different tools angles between cutting prameters: (a) cutting force; (b) contact area; (c) contact edge length.

To avoid low-speed breakage, determine other parameters besides the milling speed, change the cutting speed, and obtain a maximum bending stress at each cutting speed, so that the maximum bending stress is less than the cutting speed value of the bending strength of the tool. The qualitative relationship between maximum bending stress and cutting speed is shown in Figure 20.

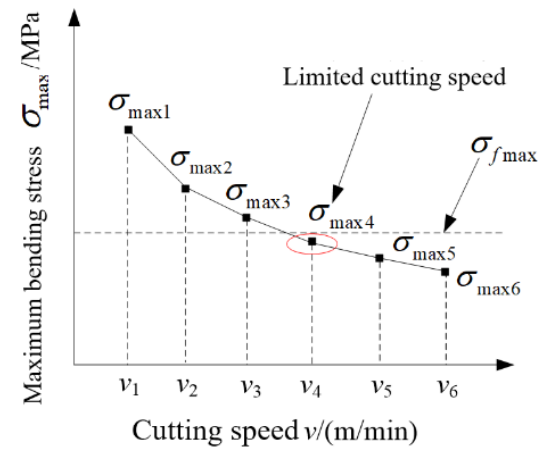

Figure 20. Determination of limit cutting speed.

In summary, by studying the influence of cutting speed on the failure of the hardened steel tool in the intermittent processing of PCBN tools, it was found that the main tool failure modes of the hardened steel of the PCBN tool are edge chipping, low-speed impact damage, flank wear, 
and high- speed fatigue damage. The early damage form was mainly the low-speed damage caused by large-scale damage of the flank face and shell-shaped damage of the rake face. When applying PCBN tools to hardened steel for milling, the early damage should be avoided as much as possible. To prevent premature damage, the following aspects should be taken: (1) The quenching hardness of the workpiece should be uniform, and the hard spots in the workpiece should be avoided as much as possible. (2) Avoid the milling speed that produced a low-speed breakage, so that the tool can be used within the safe milling speed range. (3) Try to ensure the grinding accuracy of the PCBN tool edge.

In future research, the suitable milling speed of the PCBN tool under different parameters can be quantitatively calculated by the combination of simulation and experiment. Moreover, other kinds of tools with different size or materials will be used to explore the applicability of the model. The results will provide a reference for tool design and process parameter Optimization.

\section{Conclusions}

The tool failure of PCBN cutting tool milling of hardened steel under low-speed and high-speed conditions was studied.

Under high-speed conditions, the failure modes were the flank wear, peeling of the surface material of the rake face, and high-speed fatigue damage of the flank face. The tool failure was mainly caused by mechanical wear, diffusion wear, and oxidative wear. The chamfering cutter generated thermal fatigue crack at the highest cutting temperature of the cutting edge. After the crack was expanded, the surface of the rake surface was peeled off. Moreover, due to the alternating mechanical and thermal stress, the worn tool was prone to a large area of high-speed fatigue damage on the flank face.

Under low-speed conditions, the failure modes were the chipping of the tooltip and the large damaged surface of the flank face. Large-scale damage of the flank surface of the PCBN cutting tool may occur due to the massive bending stress of the tool, which is higher than the tool material itself because of the large cutting force. To avoid the low-speed damage of hardened steel in the intermittent processing of PCBN tools, a limit milling speed model is proposed by analyzing the bending stress of tool contact, and the cutting speed should be higher than the limit speed to avoid low-speed damage while processing using PCBN cutting tool.

The present study showed the wear characteristics of the machining process and proposed a solution to avoid low-speed damage, which provides a theoretical basis for the following tool optimization and quantitative process parameter optimization.

Author Contributions: Conceptualization, X.W. and J.M.; Data curation, G.W. and X.Z.; Formal analysis, G.W. and J.M.; Funding acquisition, X.W.; Investigation, G.W. and X.W.; Methodology, G.W. and J.M.; Project administration, X.W.; Resources, G.W.; Supervision, X.W.; Visualization, X.Z.; Writing-original draft, G.W. and X.W.; Writing—review and editing, G.W., X.Z., X.W., and J.M.

Funding: This work was financially supported by the National Science Foundation of China (Grant No. 51575144) and Basic Research Projects of the "Science and Technology Talents" Program (LGYC2018JC042).

Conflicts of Interest: The authors declare no conflict of interest.

\section{References}

1. Liu, X.; Jiang, Y.; Wu, S. Research on the Technical Progress of Milling for Hardened Steel Mould of Automotive Covering Parts. Chin. J. Mech. Eng. 2016, 52, 35-57. [CrossRef]

2. Biondani, F.G.; Bissacco, G. Effect of cutting edge micro geometry on surface generation in ball end milling. CIRP Ann. 2019, 68, 571-574. [CrossRef]

3. Kasim, M.S.; Hafiz, M.S.A.; Ghani, J.A.; Haron, C.H.C.; Izamshah, R.; Sundi, S.A.; Mohamed, S.B.; Othman, I.S. Investigation of surface topology in ball nose end milling process of Inconel 718. Wear 2018, 426-427, 1318-1326. [CrossRef]

4. Urbikain, G.; de Lacalle, L.N.L. Modelling of surface roughness in inclined milling operations with circle-segment end mills. Simul. Modell. Pract. Theory 2018, 84, 161-176. [CrossRef] 
5. Pelayo, G.U. Modelling of static and dynamic milling forces in inclined operations with circle-segment end mills. Precis. Eng. 2019, 56, 123-135. [CrossRef]

6. Nguyen, H.T.; Hsu, Q.C. Surface Roughness Analysis in the Hard Milling of JIS SKD61 Alloy Steel. Appl. Sci. 2016, 6, 172. [CrossRef]

7. Tsai, M.Y.; Chang, C.T.; Ho, J.K. The Machining of Hard Mold Steel by Ultrasonic Assisted End Milling. Appl. Sci. 2016, 6, 373. [CrossRef]

8. Luo, M.; Luo, H.; Zhang, D.; Tang, K. Improving tool life in multi-axis milling of Ni-based superalloy with ball-end cutter based on the active cutting edge shift strategy. J. Mater. Process. Technol. 2018, 252, 105-115. [CrossRef]

9. Yıldırım, Ç.V.; Kıvak, T.; Erzincanlı, F. Tool wear and surface roughness analysis in milling with ceramic tools of Waspaloy: A comparison of machining performance with different cooling methods. J. Brazilian Soc. Mech. Sci. Eng. 2019, 41, 83. [CrossRef]

10. Hegab, H.; Umer, U.; Soliman, M.; Kishawy, H.A. Effects of nano-cutting fluids on tool performance and chip morphology during machining Inconel 718. Int. J. Adv. Manuf. Technol. 2018, 96, 3449-3458. [CrossRef]

11. Ghani, M.; Abukhshim, N.; Sheikh, M. An investigation of heat partition and tool wear in hard turning of HI3 tool steel with CBN cutting tools. Int. J. Adv. Manuf. Technol. 2008, 39, 874-888. [CrossRef]

12. Liu, X.; Meng, A.; Chen, L. Critical Hardness when Hard-Dry Cutting GCr15. Chin. J. Mech. Eng. 2000, 36, 13-16. [CrossRef]

13. Dureja, J.S.; Gupta, V.K.; Vishal, S.S. Optimization of flank wear and surface roughness for CBN-TiN tools during dry hard turning of hot work die steel. Indian J. Eng. Mat. Sci. 2010, 7, 129-147.

14. Domenico, U.; Fabrizio, M.; Jawahir, I.S. The effects of cryogenic cooling on surface integrity in hard machining: A comparison with dry machining. CIRP Ann. Manuf. Technol. 2012, 61, 103-106.

15. Lahiff, C.; Gordon, S.; Phelan, P. PCBN tool wear modes and mechanisms in finish hard turning. Robot. Comput.-Integr. Manuf. 2007, 23, 638-644. [CrossRef]

16. Cantero, J.L.; Díaz-Álvarez, J.; Infante-García, D.; Rodríguez, M.; Criado, V. High Speed Finish Turning of Inconel 718 Using PCBN Tools under Dry Conditions. Metals 2018, 8, 192. [CrossRef]

17. Díaz-Álvarez, J.; Criado, V.; Henar, M.; José, L.C. PCBN Performance in High Speed Finishing Turning of Inconel 718. Metals 2018, 8, 582. [CrossRef]

18. Huang, Y.; Dawson, T. Tool crater wear depth modeling in CBN hard turning. Wear 2005, 258, $1455-1461$. [CrossRef]

19. Koshy, P.; Dewes, R.C.; Aspinwall, D.K. High speed end milling of hardened AISI D2 tool steel (58 HRC). J. Mater. Process. Technol. 2002, 127, 266-273. [CrossRef]

20. Aslan, E. Experimental investigation of cutting tool performance in high speed cutting of hardened X210 Cr12 cold-work tool steel (62 HRC). Mater. Des. 2005, 26, 21-27. [CrossRef]

21. Masato, O.; Akira, H.; Ryutaro, T.; Takashi, U. Cutting performance of PVD-coated carbide and CBN tools in hardmilling. Int. J. Mach. Tools Manuf. 2011, 51, 127-132.

22. Bala, M.G.; Biswanath, M.; Sukamal, G. Experimental investigations while hard machining of DIEVAR tool steel (50 HRC). Int. J. Adv. Manuf. Technol. 2010, 51, 853-869.

23. Wojciechowski, S.; Twardowski, P. Tool life and process dynamics in high speed ball end milling of hardened steel. Procedia. CIRP. 2012, 1, 289-294. [CrossRef]

24. Wojciechowski, S.; Maruda, R.W.; Barrans, S.; Nieslonv, P.; Krolczyk, G.-M. Optimisation of machining parameters during ball end milling of hardened steel with various surface inclinations. Measurement 2017, 111, 18-28. [CrossRef]

25. Wojciechowski, S.; Maruda, R.W.; Królczyk, G.M.; Niesłony, P. Application of signal to noise ratio and grey relational analysis to minimize forces and vibrations during precise ball end milling. Precis. Eng. 2018, 51, 582-596. [CrossRef]

26. Fatih, T.; Oguz, C.; Mehmet, C.K. Investigation of TiN Coated CBN and CBN Cutting Tool Performance in Hard Milling Application. Chin. J. Mech. Eng. 2011, 5, 417-424.

27. Chou, Y.K.; Evans, C.J. Cubic boron nitride tool wear in interrupted hard cutting. Wear 1999, 225-229, 234-245. [CrossRef]

28. Chou, Y.K. Hard turning of M50 steel with different microstructures in continuous and intermittent cutting. Wear 2003, 255, 1388-1394. [CrossRef] 
29. Ko, T.J.; Kim, H.S. Surface integrity and machineability in intermittent hard turning. Int. J. Adv. Manuf. Technol. 2001, 18, 168-175. [CrossRef]

30. Boing, D.; Schroeter, R.B.; Oliveira, A.J. Three-dimensional wear parameters and wear mechanisms in turning hardened steels with PCBN tools. Wear 2018, 398, 69-78. [CrossRef]

31. Saketi, S.; Sveen, S.; Gunnarsson, S.; M'Saoubi, R.; Olsson, M. Wear of a high CBN content PCBN cutting tool during hard milling of powder metallurgy cold work tool steels. Wear 2015, 332-333, 752-761. [CrossRef]

(C) 2019 by the authors. Licensee MDPI, Basel, Switzerland. This article is an open access article distributed under the terms and conditions of the Creative Commons Attribution (CC BY) license (http://creativecommons.org/licenses/by/4.0/). 